\title{
BIPOLAR SALVAGE SHOULDER ARTHROPLASTY
}

\author{
FOLLOW-UP IN 14 PATIENTS
}

\author{
MICHAEL WATSON \\ From Guy's Hospital, London, England
}

\begin{abstract}
A bipolar spacer was inserted for severe arthritic $A_{\text {destruction of the shoulder in } 14 \text { patients, and }}$ followed up for a mean of 5.9 years. In one patient the operation failed because of infection. Two others required revision for loss of low-friction properties which caused loosening of the humeral component.

At the end of the follow-up all the patients showed improvement. The Hospital for Special Surgery pain score had increased from 5.3 to 18.9 and the movement score from 7.5 to 20.1 .
\end{abstract}

J Bone Joint Surg [Br] 1996;78-B:124-7.

Received 15 May 1995; Accepted 27 June 1995

Gross destruction of the humeral head with severe damage to the rotator cuff is an unusual and crippling cause of shoulder symptoms (Dines et al 1993). Since the degree of damage is too severe to allow conventional replacement arthroplasty such patients are often offered an arthrodesis or an excision arthroplasty (Kraulis and Hunter 1976; Clifford 1981; Tanner and Cofield 1983; Hawkins and Angelo 1987; Cofield 1988).

A bipolar prosthesis has been developed for use in these patients which stabilises the shoulder and allows movement. It consists of a freely mobile sphere in the subacromial space which articulates with a peg on a cemented humeral stem.

\section{PATIENTS AND METHODS}

Fourteen patients were treated over a ten-year period. Their ages ranged from 60 to 73 years; there were ten women and four men. The dominant arm was affected in ten (Table I).

Ten had had a four-part fracture (Neer 1970). All had had operative treatment which had failed. Five had gross malunion of tuberosity fractures, nonunion of a surgical neck

M. Watson, MA, MRCP, FRCS, Consultant Orthopaedic Surgeon Guy's Hospital, St Thomas' Street, London SE1 9RT, UK.

(C)1996 British Editorial Society of Bone and Joint Surgery 0301-620X/96/11113\$2.00 fracture, complete loss of the rotator cuff and collapseerosion of both articular surfaces (Fig. 1). In the other five patients the pattern was similar but the surgical neck fracture had healed with malunion (Fig. 2). Four patients were suffering the late effects of rheumatoid arthritis, with gross destruction of the humeral head, the glenoid process and the rotator cuff (Fig. 3). They all had only a small amount of painful movement.

All previous surgical wounds had healed and all patients had active deltoid muscles.

A stainless-steel ball $5 \mathrm{~cm}$ in diameter was bored radially to take a polyethylene cylindrical sleeve (internal diameter $1 \mathrm{~cm}$ ). A corresponding stainless-steel peg was machined at the end of a $12 \mathrm{~cm}$ metal stem, fluted for cement fixation (Biomet, Bridgend, UK) (Fig. 4).

The ball was inserted into the subacromial space after excision of sufficient bony fragments, scar tissue and glenoid to allow the equator of the ball to be at or medial to the lateral margin of the coracoacromial arch, thereby stabilising it.

The stem was cemented into the humerus after resection of the humeral head at a level which made possible a snug stable reduction of the assembled prosthesis. Usually, the humerus had migrated proximally, and the resection level allowed restoration of humeral length with normal tension of the deltoid muscle (Fig. 5). No attempt was made to

\begin{tabular}{|c|c|c|c|c|}
\hline Case & $\begin{array}{l}\text { Age } \\
(\mathbf{y r})\end{array}$ & Sex & Side & Lesion \\
\hline 1 & 71 & $\mathrm{~F}$ & Dominant & Rheumatoid arthritis \\
\hline 2 & 62 & $\mathrm{~F}$ & Non-dominant & Fracture \\
\hline 3 & 69 & M & Dominant & Fracture \\
\hline 4 & 73 & $\mathrm{~F}$ & Dominant & Fracture \\
\hline 5 & 60 & M & Dominant & Fracture \\
\hline 6 & 71 & $\mathrm{~F}$ & Dominant & Rheumatoid arthritis \\
\hline 7 & 70 & $\mathrm{~F}$ & Dominant & Rheumatoid arthritis \\
\hline 8 & 61 & $\mathrm{~F}$ & Non-dominant & Fracture \\
\hline 9 & 67 & $\mathrm{~F}$ & Dominant & Fracture \\
\hline 10 & 73 & M & Non-dominant & Fracture \\
\hline 11 & 72 & $\mathrm{~F}$ & Dominant & Rheumatoid arthritis \\
\hline 12 & 69 & $\mathrm{~F}$ & Dominant & Fracture \\
\hline 13 & 64 & M & Non-dominant & Fracture \\
\hline 14 & 67 & $\mathrm{~F}$ & Dominant & Fracture \\
\hline
\end{tabular}




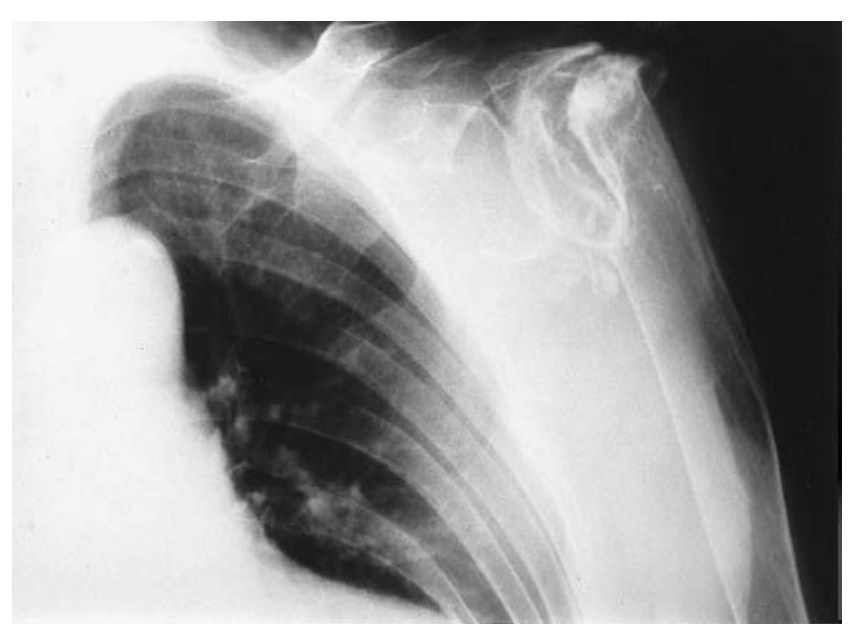

Fig. 1

Case 3. Radiograph showing a severely damaged shoulder due to nonunion and destruction of bone and soft tissue after a four-part fracture.

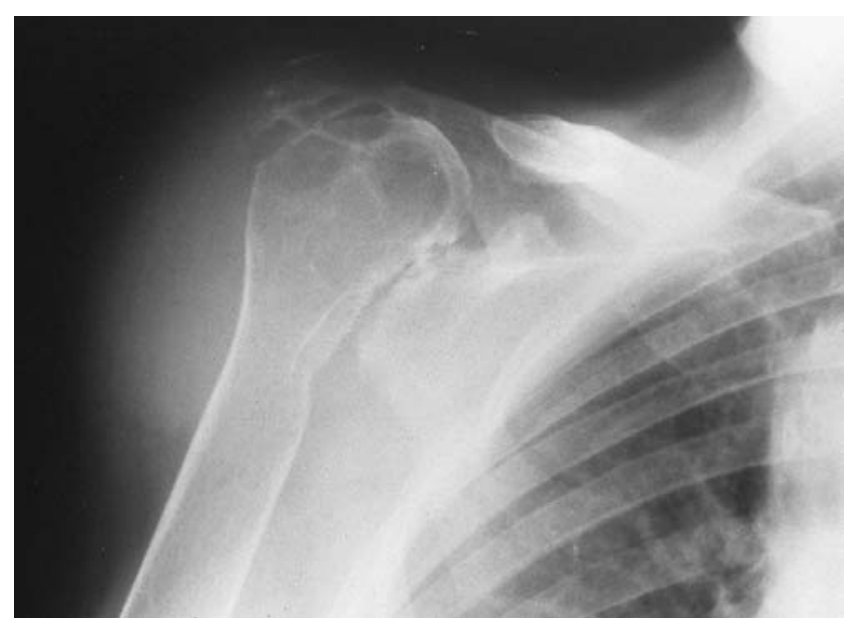

Fig. 3

Case 7. Severe rheumatoid arthritis with gross erosion of the glenoid process, medial and proximal migration of the humeral head, loss of the rotator cuff and lysis of the lateral end of the clavicle. There are large 'cysts' in the humeral head.

close the soft tissues around the prosthesis. The deltopectoral space, opened during the approach by external rotation and elevation, closed spontaneously on lowering the arm; only skin was sutured. Gentle passive mobilisation was begun immediately after the operation and active movements were encouraged as soon as postoperative pain allowed.

The patients were so severely disabled that preoperative testing of function and strength was meaningless. Therefore only range of motion and pain were assessed, both before and after operation, using the Hospital for Special Surgery (HSS) scoring system modified to exclude function and muscle strength (Table II; Dines et al 1993). In this system 30 points were allocated for lack of pain and 25 for range of movement, a normal shoulder scoring 55. An excellent

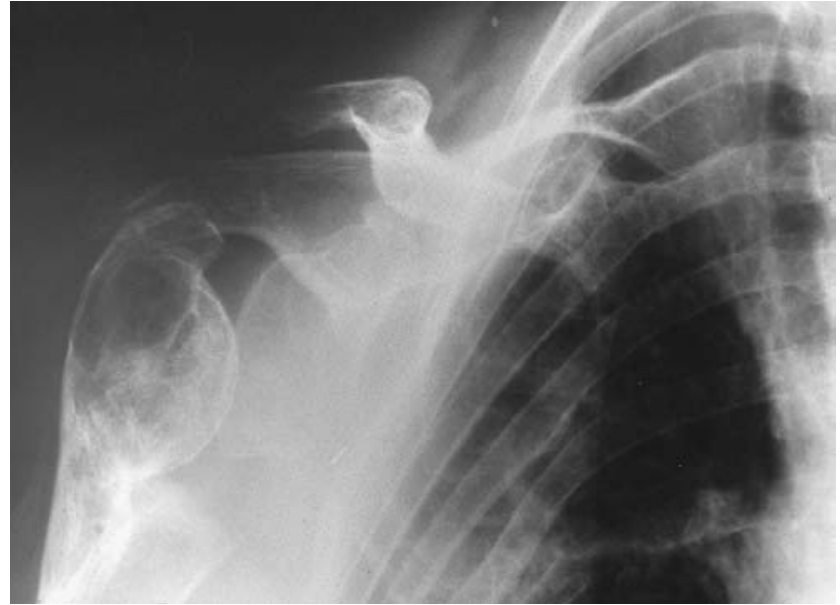

Fig. 2

Case 10. Malunion of a four-part fracture with valgus deformity at the level of the surgical neck, nonunion of the anatomical neck fracture and obliteration of the subacromial space by the displaced greater tuberosity.

result on this scale scored 47 to 55 , good 38 to 46 , fair 33 to 37 , and failure less than 33 .

\section{RESULTS}

The average follow-up was 5.9 years (2.5 to 10) (Table III).

Complications. There were no postoperative dislocations. One patient (case 14) developed a severe infection after six months. She had had two earlier procedures for a four-part fracture; one used Rush nails and the other was a hemi-

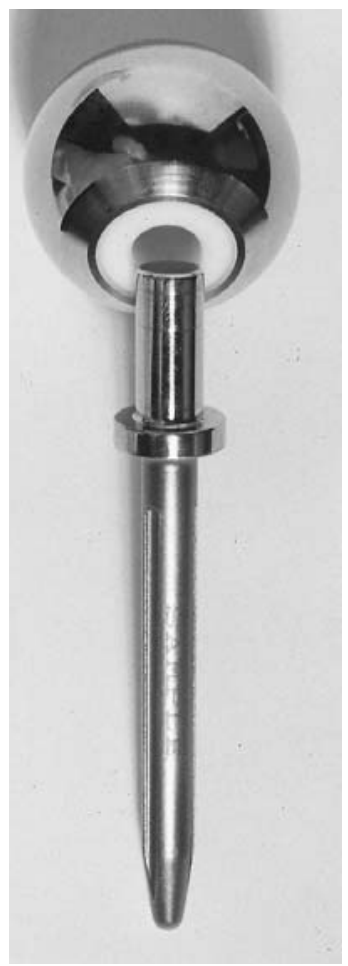

Fig. 4

The type of prosthesis used. A $5 \mathrm{~cm}$ diameter stainless-steel ball has a radial hole $1 \mathrm{~cm}$ in diameter lined with polyethylene. A reciprocally mastem is fluted for cement fixation in the shaft of the humerus. chined peg articulates with this. The 


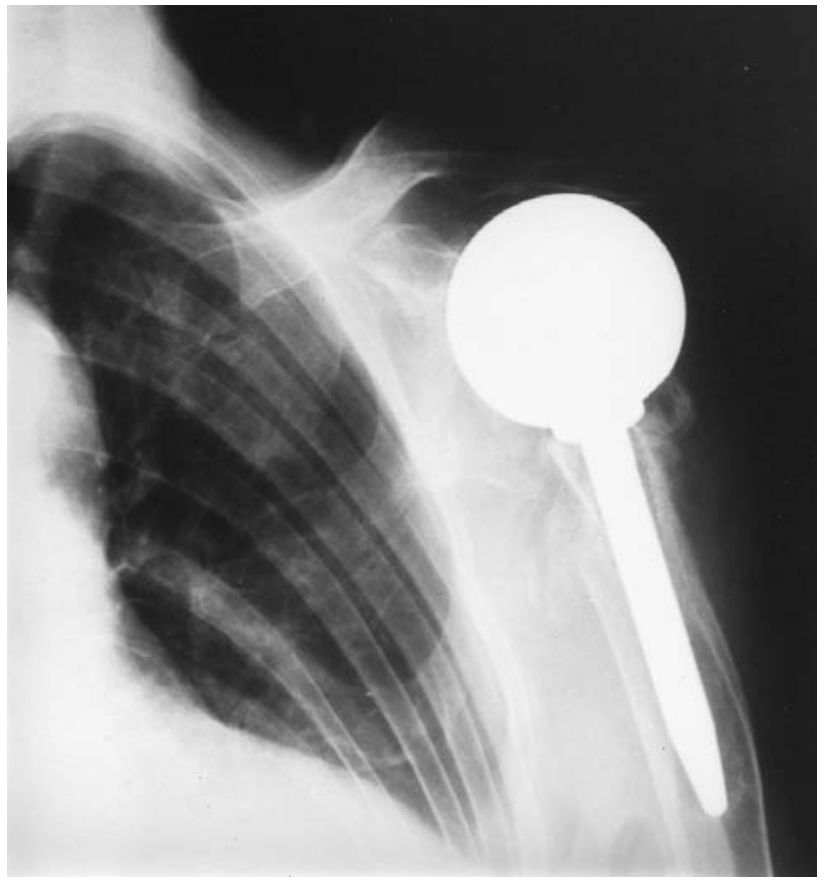

Fig. 5

Case 3. The prosthesis in situ. The remnants of the erosion of the humerus shown in Figure 1 can be seen. Humeral length has been restored and the sphere is stabilised in the subacromial space by medialisation.

arthroplasty using a conventional prosthesis. Exchange replacement of the bipolar prosthesis and treatment with appropriate antibiotics failed to control the infection. It eventually settled only when all the metal, cement and granulation tissue had been removed. She was left with a small amount of painful movement which was an improvement, although small, on her original condition (Table III).
Table II. Modified Hospital for Special Surgery (HSS) shoulder score

\begin{tabular}{lr}
\hline & Score \\
\hline Pain & \\
On movement & 15 \\
$\quad$ None & 10 \\
$\quad$ Mild to occasional, medication & 5 \\
$\quad$ Moderate, tolerable & 0 \\
$\quad$ Severe, disabling, narcotics & \\
At rest & 15 \\
$\quad$ None & 10 \\
$\quad$ Mild, medication & 5 \\
$\quad$ Moderate & 0 \\
$\quad$ Severe & 30 \\
Maximum & \\
& \\
Range of movement (1 point per 20 & \\
Forward flexion maximum & 8 \\
Abduction maximum & 7 \\
Adduction maximum & 2 \\
Internal rotation maximum & 5 \\
External rotation maximum & 3 \\
Maximum & 25 \\
\hline
\end{tabular}

Two other patients (cases 8 and 10) developed increasing pain and stiffness during follow-up, in spite of initially gratifying results. Both had loosening of the humeral stem, and at revision it was found that the internal joint in the prosthesis had become very stiff. Exchange replacement was satisfactory in both (Table III).

At the end of follow-up the mean HSS pain score had improved from 5.3 preoperatively to 18.9 . The mean movement score had improved from 7.5 to 20.1 . The mean preoperative HSS overall score was 12.9 (failure) and at the end of follow-up it was 39 (good). Although improved, two patients (cases 12 and 14) were rated as failures at the end of follow-up. One patient (case 13) was rated fair and 11 as good. The two patients (cases 8 and 10) who had had

Table III. The modified HSS score preoperatively and at the end of follow-up in 14 patients

\begin{tabular}{|c|c|c|c|c|c|c|c|}
\hline \multirow[b]{2}{*}{ Case } & \multirow{2}{*}{$\begin{array}{l}\text { Length of } \\
\text { follow-up } \\
\text { (yr) }\end{array}$} & \multicolumn{2}{|l|}{ Pain } & \multicolumn{2}{|c|}{ Movement } & \multicolumn{2}{|l|}{ Score } \\
\hline & & Preop & At follow-up & Preop & At follow-up & Preop & At follow-up \\
\hline 1 & 4 & 5 & 25 & 6 & 19 & 11 & 44 \\
\hline 2 & 6 & 5 & 20 & 4 & 18 & 9 & 38 \\
\hline 3 & 7 & 10 & 20 & 6 & 21 & 16 & 41 \\
\hline 4 & 4 & 5 & 25 & 3 & 21 & 8 & 46 \\
\hline 5 & 2.5 & 0 & 25 & 4 & 22 & 4 & 47 \\
\hline 6 & 3 & 5 & 20 & 6 & 23 & 11 & 43 \\
\hline 7 & 7 & 5 & 20 & 9 & 20 & 14 & 40 \\
\hline 8 & 9 & 10 & 20 & 8 & 22 & 18 & 42 \\
\hline 9 & 10 & 5 & 15 & 8 & 23 & 13 & 38 \\
\hline 10 & 8 & 5 & 20 & 12 & 20 & 17 & 40 \\
\hline 11 & 7 & 5 & 20 & 11 & 20 & 16 & 40 \\
\hline 12 & 7 & 5 & 15 & 7 & 17 & 12 & 32 \\
\hline 13 & 4 & 5 & 15 & 10 & 20 & 15 & 35 \\
\hline 14 & 4 & 5 & 5 & 12 & 15 & 17 & 20 \\
\hline Mean & 5.9 & 5.3 & 18.9 & 7.5 & 20.1 & 12.9 & 39 \\
\hline
\end{tabular}


revision for loss of low-friction properties in the prosthesis eventually both had good results (Table III).

\section{DISCUSSION}

In these severely disabled patients the improvement, although moderate by conventional standards, was considered worthwhile.

The two technical failures in the series should be avoidable in the future. The loss of low-friction properties was probably due to swelling of the polyethylene sleeve, and greater tolerance is planned in future prostheses to prevent this.

While the follow-up is adequate, the long-term outlook for these patients is of course unknown. It is possible that progressive erosion of the ball against its socket will occur with pain and loss of movement. This is a cause for concern and continued follow-up will help to assess this problem.

Conclusions. A bipolar spacer in the subacromial space offers the patient with a severely disabled shoulder a reasonably good chance of a useful and comfortable joint when other procedures seem inappropriate.

The inspiration for the prosthesis came from the late Professor L. Kessel to whose memory this study is respectfully dedicated.

No benefits in any form have been received or will be received from a commercial party related directly or indirectly to the subject of this article.

\section{REFERENCES}

Clifford PC. Fractures of the neck of humerus: a review of the late results. Injury 1981;12:91-5.

Cofield RH. Comminuted fractures of the proximal humerus. Clin Orthop 1988;230:49-57.

Dines DM, Warren RF, Altchek DW, Moeckel B. Posttraumatic changes of the proximal humerus: malunion, nonunion and osteonecrosis. Treatment with modular hemiarthroplasty or total shoulder arthroplasty. J Shoulder Elbow Surg 1993;2:11-21.

Hawkins RJ, Angelo RL. Displaced proximal humeral fractures: selecting treatment, avoiding pitfalls. Orthop Clin North Am $1987 ; 18: 421-39$

Kraulis J, Hunter G. The results of prosthetic replacement in fracturedislocations of the upper end of the humerus. Injury 1976;8:129-31.

Neer CS II. Displaced proximal humeral fractures. Part II. Treatment of three-part and four-part displacement. J Bone Joint Surg [Am] 1970;52-A:1090-103.

Tanner MW, Cofield RH. Prosthetic arthroplasty for fractures and fracture-dislocations of the proximal humerus. Clin Orthop $1983 ; 179: 116-28$ 